\title{
Cellular Growth in Various Regions of the Developing Rat Brain
}

\author{
Irving Fish and Myron Winrak ${ }^{[22]}$ \\ Departments of Pediatrics and Neurology, Cornell University Medical College, \\ New York, New York, USA
}

\begin{abstract}
Extract
The cellular growth patterns in whole brain, cerebrum, cerebellum, hippocampus, and brainstem were examined in rats between 6 and 22 days of age. When weight alone was measured, little difference was seen between the various regions; however, when cell number (DNA) or protein per cell (protein: DNA) was measured, regional differences became very striking.

In the cerebellum, DNA content increased 8.5 fold between 6 and 17 days and subsequently tapered off. The protein:DNA ratio declined during this period. Although the increase in cell number in the cerebrum was only 2.5 fold, it continued until 21 days, at which time the experiment was terminated. After 10 days there was also an increase in the protein:DNA ratio. In the brainstem, there was a modest increase in cell number between 6 and 14 days. After 10 days the protein:DNA ratio increased 4 fold. In the hippocampus, there was a discrete increase in cell number only between 14 and 17 days.

These data demonstrate the existence of distinct regional patterns of cellular growth during postnatal maturation of rat brain.
\end{abstract}

\section{Speculation}

The brain, although often viewed as a discrete organ, is composed of a number of anatomically distinct regions that perform separate and unique functions. Previous data from this laboratory have shown that cell division ceases in whole rat brain by 21 days postnatally and in whole human brain by six months of age. This study demonstrates that various regions of rat brain have different rates of cell division and that the entire pattern of cellular growth is regionally specific. Since certain functions are regionally controlled, it is possible that the regional growth patterns described here have functional correlates.

Alteration in the environment (nutrition) is known to affect the rate of cell division in whole brain. It is possible that environmental effects may be regionally specific. By studying the effects of environmental stimuli (anoxia or malnutrition) on regional growth patterns and correlating these effects with functional changes, it may be possible to relate cellular changes to functional deficits. 


\section{Introduction}

Organ growth is not a homogeneous process, especially in brain. Specific regions may grow at varying rates. Moreover, within any given region, growth can occur by an increase in cell number (hyperplasia) or by an increase in the size of individual cells (hypertrophy). Simply measuring increments in weight, volume, or density will not distinguish between these two biologically different types of growth. This distinction can be clearly made, however, with biochemical measurements. Since DNA is not only located almost entirely in the nucleus, but is also fixed in quantity in every diploid nucleus within a given species $[6,14]$, an increase in total organ DNA represents an increase in the number of cells. The Purkinje cells of the cerebellum are polyploid, as are a few cells in the forebrain [12]. In both areas, however, they constitute such a small percentage of the total number of cells that they do not significantly affect the general principle that an increase in DNA content is indicative of an increase in cell number. The protein: DNA ratio reflects the average protein content per cell and the RNA:DNA ratio represents the average RNA content per cell.

During the postnatal development of the rat, DNA content of whole brain increases linearly until about the 17th day and then levels off. In contrast, protein content continues to increase linearly until 99 days of age [17]. Thus, postnatal growth in whole rat brain occurs initially by hyperplasia and subsequently by hypertrophy. Brain, however, is composed of various regions known to control specific functions. These regions are made up of different cell populations and demonstrate different cellular migratory patterns [1, $3,15]$. Our studies examine cellular growth in four different regions of the developing rat brain.

\section{Materials and Methods}

Sprague Dawley strain rats were nursed in litters of ten. Animals were sacrificed at $6,8,10,17$, and 21 days of age. In order to keep the size of the nursing group constant, animals from another litter replaced the animals killed. The brains were removed immediately and divided into cerebrum, cerebellum, hippocampus, and brainstem. The cerebellum was separated by blunt dissection at the cerebellar peduncles. The brainstem boundary was considered to be the thalamus and the hypothalamus above and the bottom of the medulla below. Since the hippocampus is quite large and distinct in the rat, it was isolated by blunt dissection through the cerebrum. The cerebrum was considered to be all matter in the forebrain above the thalamus and the hypothalamus exclusive of the hippocampus. Protein,
Fig. 1. Weight of the regions of the developing rat brain versus days. Whole brain is represented as $0.5 \times$ the weight in order to get it on the figure. Each point represents a minimum of three animals. The ranges are indicated.

RNA, and DNA were extracted by the method of Schmidt and Thannhauser [16]. Protein was determined by the method of LowRy et al. [13]. RNA was determined by the orcinol reaction [9]. DNA was determined by BuRTon's modification of the diphenylamine reaction [7], which had been standardized against the fluorometric method of KISSANE and RoBINS [11] and shown to agree within 2\%. Complete details of the methods have been described previously [17].

\section{Weight \\ Results}

Whole brain increased in weight 2.5 fold between 6 and 21 days (fig. 1 ). In cerebrum, brainstem, and hippocampus, weight increased 2 fold, while in cerebellum, it increased 6 fold. The regional patterns of increase in weight showed only slight variation from that in whole brain. Weight of whole brain and cerebrum increased in a curvilinear fashion; that of cerebellum increased linearly between 6 and 21 days. Hippocampus demonstrated a discrete increase in weight only between 10 and 17 days. Weight in brainstem increased slowly between 6 and 14 days and increased more rafidly thereafter.

\section{Whole Brain}

Values for DNA, RNA, and protein content in whole brain were obtained by adding the sum of the parts (fig.2). DNA content increased 3 fold from 1.02 to $3.23 \mathrm{mg}$ between 6 and 17 days and increased very little thereafter. RNA content increased from 2.18 to $4.91 \mathrm{mg}$ and then tapered off. In contrast, protein content continued to increase linearly from 4.92 to 218.7 $\mathrm{mg}$ until 21 days, at which time the experiment was terminated.

\section{Cerebellum}

The rate of cell division in cerebellum exceeded that in any other region from 6 through 17 days (fig. 3 ). DNA content increased 8.5 fold from 0.188 to $1.58 \mathrm{mg}$ between 6 and 17 days and subsequently tapered off. Protein increased only 3 fold, from 7.7 to $26.7 \mathrm{mg}$; thus, the protein:DNA ratio or protein per cell actually decreased. Since RNA increased only 4 fold, from 0.205 to $0.850 \mathrm{mg}$, the RNA: DNA ratio also declined with growth. 

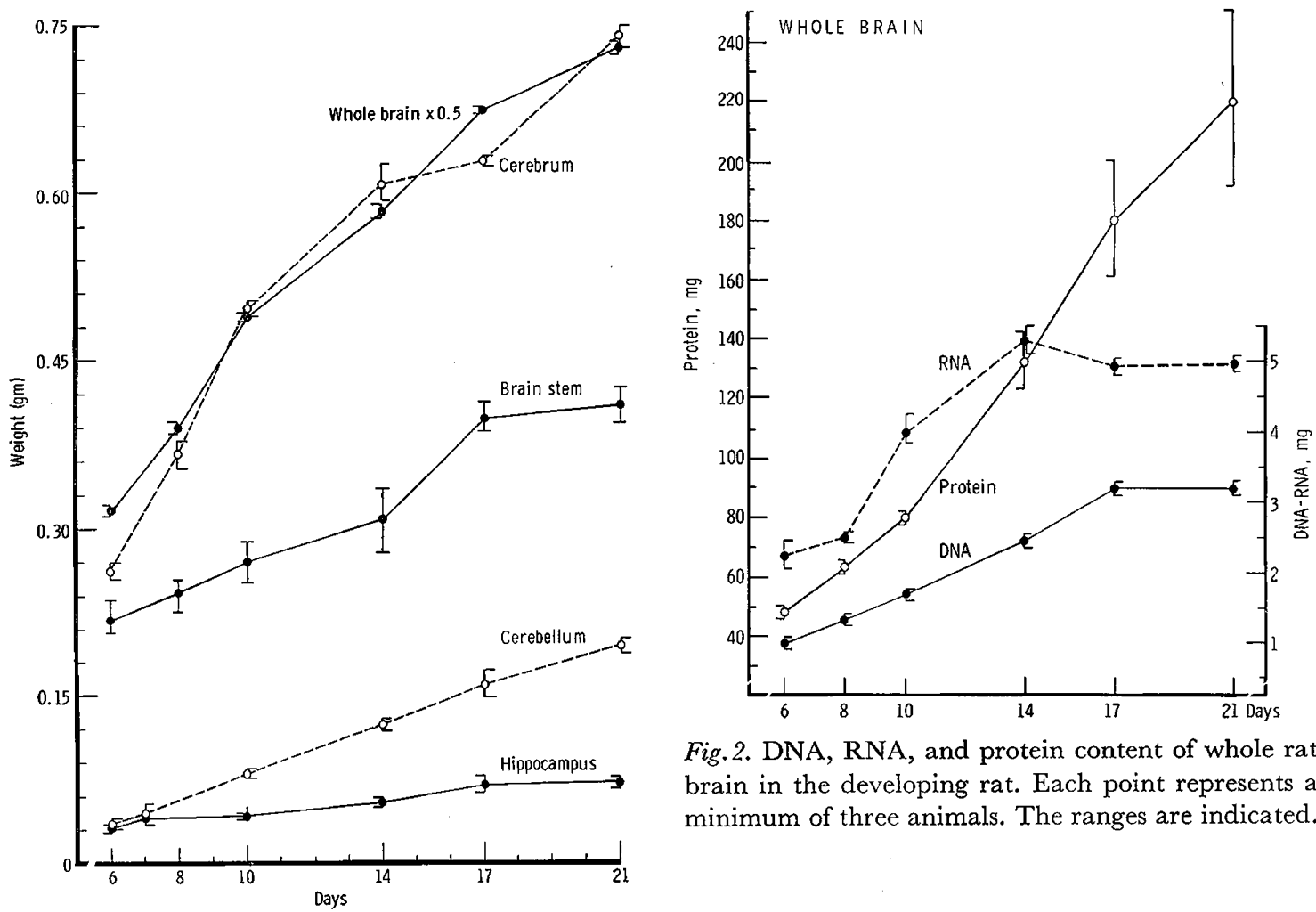

Fig. 2. DNA, RNA, and protein content of whole rat brain in the developing rat. Each point represents a minimum of three animals. The ranges are indicated.
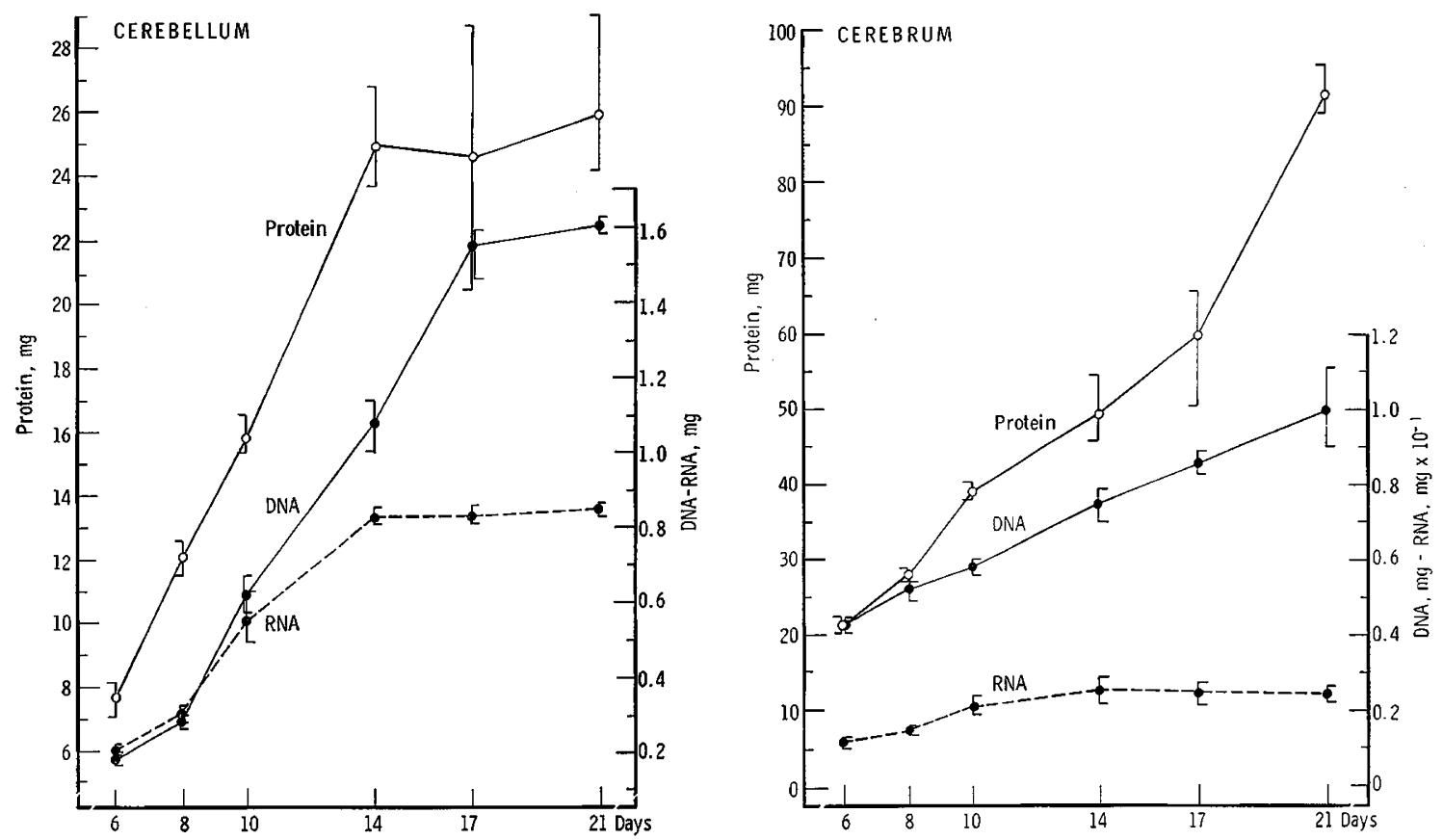

Fig.3. DNA, RNA, and protein content of the developing rat cerebellum. Each point represents a minimum of three animals. The ranges are indicated.

Fig.4. DNA, RNA, and protein content of cerebrum versus days. RNA is represented as 0.1 value in order to get it on the graph. Each point represents a minimum of three animals. The ranges are indicated. 


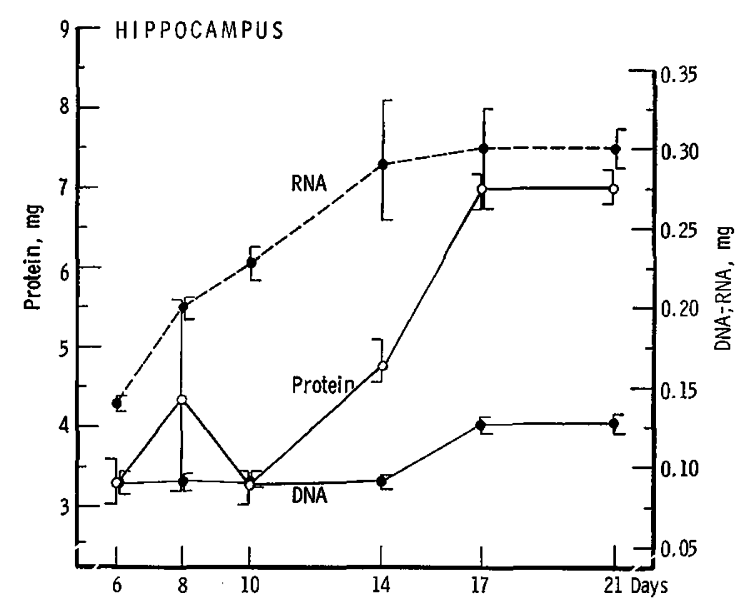

Fig.5. DNA, RNA, and protein content of hippocampus in the developing rat brain. Each point represents a minimum of three animals. The ranges are indicated.

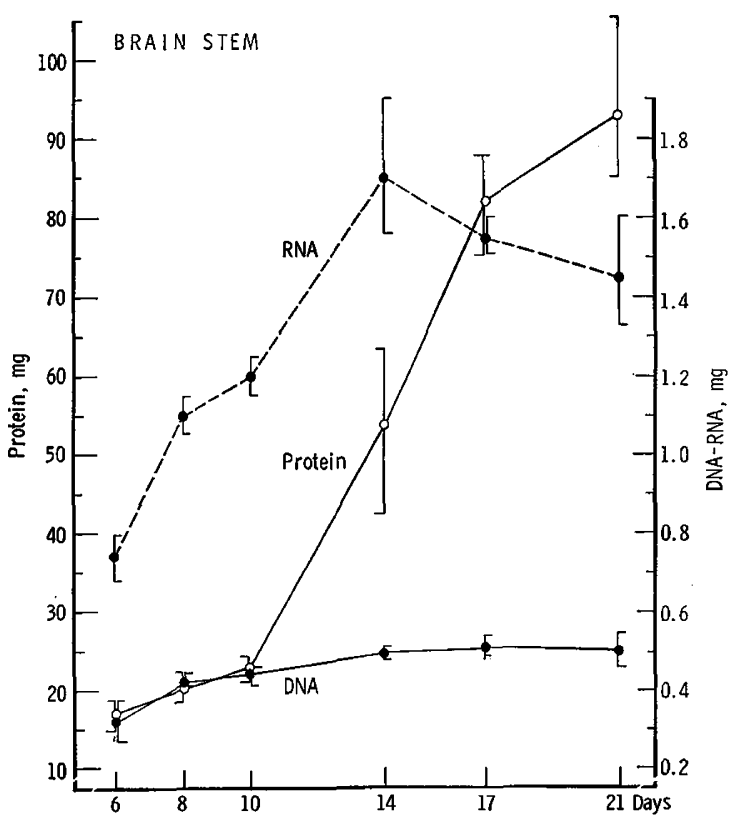

Fig.6. DNA, RNA, and protein content of brainstem in the developing rat brain. Each point represents a minimum of three animals. The ranges are indicated.

\section{Cerebrum}

Gell division in the cerebrum occurred at a slower rate than it did in the cerebellum, but persisted for a longer period of time (fig.4). DNA increased linearly from 0.428 to $1.013 \mathrm{mg}$ between 6 and 21 days, while protein increased from 21.6 to $92.3 \mathrm{mg}$. Thus, the

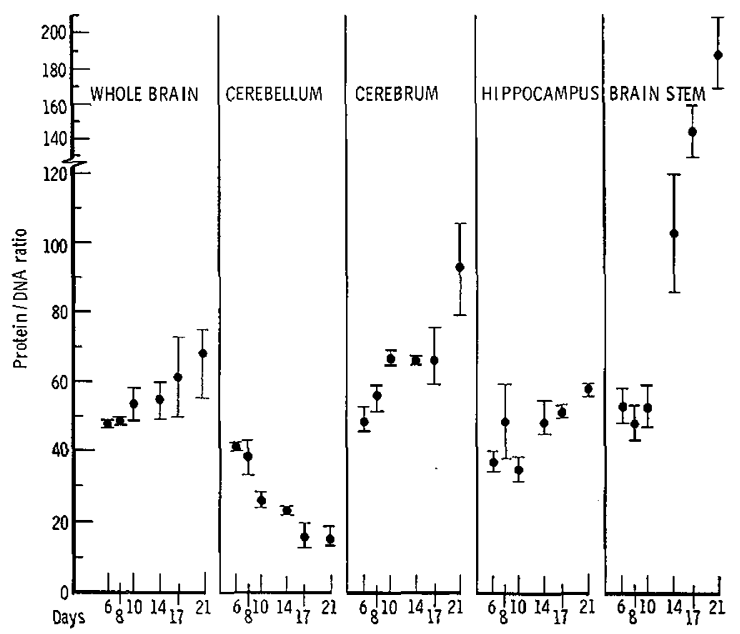

Fig.7. Protein:DNA ratios in various regions of the developing rat brain. Each point represents a minimum of three animals. The ranges are indicated.

protein:DNA ratio increased, especially after 10 days. Since RNA increased from 1.09 to $2.36 \mathrm{mg}$, the RNA: DNA ratio remained fairly constant throughout early growth.

\section{Hippocampus}

DNA content failed to increase between 6 and 14 days (fig. 5). Between 14 and 17 days there was a sudden $50 \%$ increase, from 0.088 to $0.135 \mathrm{mg}$. The increase then leveled off. The RNA content increased until 14 days and then tapered off. The exact rate of increase of protein was unclear, but it would appear that there was a slow, steady increase in protein content from $3.3 \mathrm{mg}$ at 6 days to $7.0 \mathrm{mg}$ at 17 days and then a tapering off.

\section{Brainstem}

There was a $65 \%$ increase from 0.319 to $0.503 \mathrm{mg}$ in DNA content between 6 and 14 days, and no further increase thereafter (fig.6). In contrast, protein increased 6 fold from 16.1 to $93.5 \mathrm{mg}$, most of the increase occurring after 10 days. Thus, a small increase in cell number occurred early, but most growth in the brainstem, especially after 10 days, resulted from hypertrophy.

\section{Discussion}

Simply measuring brain weight alone showed that, with the exception of the hippocampus, all regions increased linearly. Except for cerebellum, this increase occurred at approximately the same rate. Thus, the 
pattern of increments in the weight of whole brain did not seem to differ strikingly from that in the various regions.

Whole brain analysis, however, failed to reflect accurately the cellular growth patterns of the various regions. In the cerebellum, there was a marked increase in cell number between 6 and 17 days. In the cerebrum, cell number increased more slowly but for a longer period of time. In the brainstem, the increase in cell number was slowest and occurred for the shortest time.

In contrast, cell number in the hippocampus failed to increase between 6 and 14 days. Between 14 and 17 days, DNA content increased sharply and then leveled off. In the young rat, there is a region beneath the lateral ventricle that contains immature cells. The cells have been shown to migrate to the hippocampus, being present in large numbers of the 15th day [2]. Our data are consistent with these findings.

Whole brain analysis also failed to reflect the protein:DNA ratio in the various regions (fig. 7). The ratio increased steadily in cerebrum, whereas in brainstem, it remained constant between 6 and 10 days and then increased 4 fold. Although part of the protein may have come from cells originating elsewhere, it appeared that growth of the brainstem after 10 days occurred by hypertrophy. Conversely, the protein:DNA ratio in the cerebellum actually decreased during growth (fig. 7).

Previous data from this and other laboratories have indicated that the effects of certain external stimuli on the developing brain depend on the state of growth of the brain [5, 8, 10, 18]. Thus, malnutrition, when it occurs early, retards brain growth by interfering with cell division. If refeeding is initiated after the period of cell division, recovery does not take place. If, however, caloric restriction is instituted after the period of cell division has ended, no effect on DNA content or cell number is seen. Instead, the protein:DNA ratio is reduced but returns to normal when the animal is subsequently refed. Since brain growth is not homogeneous, different regions might be affected differently, depending on the cellular events occurring at the time a stimulus was active. In humans, certain stimuli such as excess phenylalanine or decreased circulating thyroxine affect the young brain more profoundly than they do the mature brain. The young brain also responds to anoxia very differently from the more mature brain [4]. Regional studies using these stimuli have not been done. It is possible that these age-dependent differences may also be related to the type of growth occurring in various regions at the time of insult.

These data suggest that if meaningful correlations are to be made between biochemical and functional changes in the brain, or between pathologic stimuli and subsequent biochemical differences, individual regions must be examined separately.

\section{References and Notes}

1. Altman, J.: Autoradiographic and histological studies of postnatal neurogenesis. II. A longitudinal investigation of the kinetics, migration and transformation of cells incorporating tritiated thymidine in infant rats with special reference to postnatal neurogenesis in some brain regions. J.comp. Neurol. 128: 431 (1966).

2. Altman, J.: Presented at the Int. Conf. of the Effect of Malnutrition on Brain Development, Massachusetts Institute of Technology, 1967.

3. Altman, J. and DAs, G.: Autoradiographic and histological studies of postnatal neurogenesis. I. A longitudinal investigation of the kinetics, migration and transformation of cells incorporating tritiated thymidine in infant rats with special reference to postnatal neurogenesis in some brain regions. J. comp. Neurol. 126: 337 (1966).

4. BANKER, B.Q.: Periventricular leukomalacia of infancy. Arch. Neurol. 7: 386 (1962).

5. Barnes, R.H.; Moore, A.A. and Reid, S.M.: Learning behavior following nutritional deprivation in early life. J.amer. Diet. Ass. 51: 34. (1967).

6. Boivin, A.; Vendrely, R. et Vendrely, G.: L'acide desoxyribonucléique du noyeau cellulaire, dépositaire des caractères héréditaires; arguments d'ordre analytique. C.R.Acad.Sci. 226: 1061 (1948).

7. Burton, K.: A study of the conditions and mechanisms of the diphenylamine reaction for the colorimetric estimation of desoxyribonucleic acid. Biochem.J. 62: 315 (1956).

8. Ghase, H.P.; Dorsey, J. and MaKhann, G.M.: The effect of malnutrition on the synthesis of a myelin lipid. Pediatrics 40: 551 (1967).

9. Dische, A.: in: E. Ghargoff and J.W.Davidson The nucleic acids, vol.I (Academic Press, New York 1955).

10. Dobbing, J. and Widdowson, E.: The effect of malnutrition and subsequent rehabilitation on myelination as measured by its composition. Brain 88 : 357 (1965).

11. Kissane, J.M. and Robins, E.: The fluorometric measurement of desoxyribonucleic acid in animal tissues with special reference to the central nervous system. J. biol. Chem. 233: 184 (1958).

12. LAPHAM, L.W.: Tetraploid DNA content of Purkinje neurons of human cerebellar cortex. Science 159: 310 (1968).

13. Lowry, O.H.; Rosebrough, N.J.; Farr, H.L. 
and Randall, R.J.: Protein measurement with the Folin phenol reagent. J.biol. Chem. 193: 265 (1951).

14. Mirsky, A.E. and Ris, H.: Variable and constant components of chromosomes. Nature, Lond. 163: 666 (1949).

15. Rakic, P. and Sidman, R.L.: Supravital DNA synthesis in the developing human and mouse brain. J. Neuropath. exp. Neurol. 27: 246 (1968).

16. Schmidt, G. and Thannhauser, S. I.: A method for the determination of desoxyribonucleic acid, ribonucleic acid and phosphoproteins in animal tissues. J. biol. Chem. 161: 83 (1945).

17. Winick, M. and Noble, A.: Quantitative changes in DNA, RNA and protein during prenatal and postnatal growth in the rat. Dev.Biol. 12: 451 (1965).

18. Winick, M. and Noble, A.: Cellular response in rats during malnutrition at various ages. J. Nutr. 89: 300 (1966).

19. Presented in part at the American Academy of Neurology Meeting, April 1968.

20. This investigation was supported in part by a special training grant from the National Institute of Neurological Diseases and Blindness NB 05064 (Dr. FISH), National Foundation Research Grant CRCS 45, and Nutrition Foundation Grant No. 357.

21. The authors wish to express their appreciation to Mrs. Laura Weinstein for her technical assistance.

22. Requests for reprints should be addressed to: $\mathrm{MY}$ Ron Winrck, M.D., Department of Pediatrics, Cornell University Medical Center, New York Hospital, 525 East 68th Street, New York, New York 10021 (USA). 